\title{
Developmental expression of the $\mathrm{Ca}^{2+}$-binding proteins calretinin and parvalbumin at the calyx of Held of rats and mice
}

\author{
Felix Felmy* and Ralf Schneggenburger \\ AG Synaptische Dynamik und Modulation and Abteilung Membranbiophysik, Max-Planck-Institut für Biophysikalische Chemie, Am \\ Fassberg 11, D-37077 Göttingen, Germany
}

Keywords: facilitation, medial nucleus of the trapezoid body (MNTB), release probability, synapse, transmitter

\begin{abstract}
$\mathrm{Ca}^{2+}$-binding proteins of the EF-hand family are widely expressed in the CNS, and contribute to intracellular $\mathrm{Ca}^{2+}$ buffering in neurons. In nerve terminals, $\mathrm{Ca}^{2+}$-binding proteins are likely to regulate transmitter release probability and synaptic short-termplasticity. Here, we investigated the developmental expression pattern of calretinin and parvalbumin at a large excitatory synapse, the calyx of Held in the medial nucleus of the trapezoid body (MNTB) of rats and mice. We used two-colour immunofluorescence imaging with primary antibodies detecting one of the $\mathrm{Ca}^{2+}$-binding proteins, and a presynaptic marker protein, Rab-3A. Calretinin was found in nerve terminals of the calyx of Held, but not in postsynaptic principal cells. The presynaptic density of Calretinin staining, and the degree of colocalization with Rab-3A increased during postnatal development (P6-P31). Surprisingly, not all calyces of Held expressed calretinin. In rats, calretinin-containing calyces were irregularly interspersed with calretinin-negative calyces, whereas in mice, calretinin-positive calyces were preferentially located in the lateral portion of the MNTB. The percentage of calretinin-positive calyces increased during development, to about $75 \%$ and $20 \%$ at P30 in rats and in mice, respectively. Parvalbumin was present in the presynaptic calyces of Held and in the nerve fibres entering the MNTB, as well as in the somata of the MNTB principal neurons. An up-regulation of calretinin and parvalbumin in calyces of Held probably increases the presynaptic $\mathrm{Ca}^{2+}$ buffering strength during postnatal development, but the unexpected heterogeneity of calretinin expression might cause differences in $\mathrm{Ca}^{2+}$ signalling and transmitter release probability between calyces of Held.
\end{abstract}

\section{Introduction}

The EF-hand $\mathrm{Ca}^{2+}$-binding proteins (CaBP) calretinin (CR), calbindin $\mathrm{D}-28 \mathrm{k}(\mathrm{CB})$ and parvalbumin (PV) are widely expressed in neurons of the CNS (Celio, 1990; Arai et al., 1991; Resibois \& Rogers, 1992). When present in nerve terminals, the $\mathrm{Ca}^{2+}$ buffering properties of CaBPs are expected to modulate transmitter release, and $\mathrm{Ca}^{2+}$-dependent forms of short-term plasticity. Interestingly, the way in which CaBPs influence $\mathrm{Ca}^{2+}$ signalling critically depends on the $\mathrm{Ca}^{2+}$-binding kinetics of the implicated CaBPs. CaBPs with relatively rapid binding kinetics, such as for example CB (Nägerl et al., 2000) and CR, will reduce the peak intracellular $\mathrm{Ca}^{2+}$ concentration $\left(\left[\mathrm{Ca}^{2+}\right]_{\mathrm{i}}\right)$ signal on a millisecond time scale (Airaksinen et al., 1997). If present at sufficiently high concentrations in nerve terminals, CaBPs with rapid binding kinetics can buffer some of the incoming $\mathrm{Ca}^{2+}$ ions before these reach the $\mathrm{Ca}^{2+}$ sensor for vesicle fusion (Edmonds et al., 2000). Thus, CaBPs can potentially decrease the transmitter release probability during basal synaptic transmission. During repetitive activity and the concomitant build-up of residual $\left[\mathrm{Ca}^{2+}\right]_{\mathrm{i}}$ in the nerve terminal, however, partial saturation of rapidly equilibrating $\mathrm{Ca}^{2+}$ buffers (Neher, 1998) reduces their buffering strength, which in turn enhances the action of residual $\left[\mathrm{Ca}^{2+}\right]_{\mathrm{i}}$ in causing

Correspondence: Dr Ralf Schneggenburger, as above.

E-mail: rschneg@gwdg.de

*Present address: The Vollum Institute, Oregon Health and Science University, Portland, OR 97239, USA. E-mail: felmyf@ohsu.edu

Received 7 May 2004, revised 22 June 2004, accepted 6 July 2004 short-term facilitation (Rozov et al., 2001; Blatow et al., 2003; Felmy et al., 2003).

CaBPs with slow $\mathrm{Ca}^{2+}$-binding kinetics, such as PV (Lee et al., 2000), probably have a different role in $\mathrm{Ca}^{2+}$ signalling. Slow $\mathrm{Ca}^{2+}$ buffers will not reduce the peak $\left[\mathrm{Ca}^{2+}\right]_{\mathrm{i}}$ signal, but delayed $\mathrm{Ca}^{2+}$ binding by the buffer will accelerate the decay of residual $\left[\mathrm{Ca}^{2+}\right]_{\mathrm{i}}$ (Atluri \& Regehr, 1996; Lee et al., 2000). In agreement with its slow $\mathrm{Ca}^{2+}$-binding properties, PV was shown to suppress the amount of transmitter release facilitation in inhibitory nerve terminals (Caillard et al., 2000; Vreugdenhil et al., 2003).

The calyx of Held synapse in the medial nucleus of the trapezoid body (MNTB) is an excitatory relay synapse in the auditory brainstem pathway, formed by globular bushy cells in the anterior ventral cochlear nucleus $(\mathrm{aVCN})$, and principal cells in the contralateral MNTB (Harrison \& Irving, 1966; Friauf \& Ostwald, 1988; Spirou et al., 1990; Kuwabara et al., 1991). The unusually large size of the calyx of Held allows direct patch-clamp recordings and $\mathrm{Ca}^{2+}$ imaging measurements to be made at these nerve terminals (Forsythe, 1994; Borst et al., 1995; Helmchen et al., 1997; Schneggenburger et al., 1999). For this reason, the calyx of Held has become a valuable model system for studying presynaptic $\mathrm{Ca}^{2+}$ signalling and $\mathrm{Ca}^{2+}$-dependent forms of short-term plasticity (see Schneggenburger et al., 2002; von Gersdorff \& Borst, 2002, for reviews). The combination of CaBPs that determines $\mathrm{Ca}^{2+}$ signalling in calyces of Held has, however, not been identified. Although it is known that the CaBPs CR, CB and PV are widely expressed in the brainstem auditory nuclei (Arai et al., 1991; Caicedo 
et al., 1996; Lohmann \& Friauf, 1996), among them the MNTB, the distribution of CaBPs on a subcellular level in the MNTB, and the developmental changes of the expression level of CaBPs in calyces of Held are unknown. Here, we have used immunocytochemical doublestaining techniques to investigate the presynaptic localization and the developmental expression pattern of CR, CB and PV in calyces of Held of rats and mice.

\section{Materials and methods}

\section{Immunocytochemistry}

Wistar rats $(n=24$; age range postnatal day P6-P31) and C57B16 mice $(n=10$; age range P6-P33) were killed by decapitation, according to a procedure approved by the local government authorities. The brain was removed quickly and placed in ice-cold Ringer solution containing (in $\mathrm{mM}$ ): $125 \mathrm{NaCl}, 25 \mathrm{NaHCO}_{3}, 2.5 \mathrm{KCl}$, $1.25 \mathrm{NaH}_{2} \mathrm{PO}_{4}, 3 \mathrm{MgCl}_{2}, 0.1 \mathrm{CaCl}_{2}, 25$ glucose, 0.4 ascorbic acid, 3 myo-inositol and 2 Na-pyruvate; $\mathrm{pH}=7.4$ when bubbled with $95 \%$ $\mathrm{O}_{2}, 5 \% \mathrm{CO}_{2}$. The hindbrain was cut off, and immersion-fixed in $4 \%$ paraformaldehyde-containing phosphate-buffered solution (PBS) for $12-18 \mathrm{~h}$ at room temperature $\left(21-24^{\circ} \mathrm{C}\right)$. Following fixation, transverse brainstem slices of $70-90 \mu \mathrm{m}$ thickness were made with a vibratome slicer (Campden Instruments), and slices containing the MNTB were further processed free-floating. Usually, 10-12 transverse slices containing the MNTB were obtained from one animal. The slices were rinsed three times with PBS, and then postfixed with $4 \%$ paraformaldehyde-containing PBS for $30 \mathrm{~min}$. Later the slices were washed three times with $0.4 \%$ Triton $\mathrm{X}-100$ containing blocking buffer. Slices were subsequently rinsed three times in blocking buffer (BF; $1 \%$ albumin dissolved in PBS), before they were further incubated in Triton-X containing BF for $1 \mathrm{~h}$. The incubation with primary antibodies was done in PBS overnight at room temperature. One of the following polyclonal antibodies against the indicated $\mathrm{CaBP}$ was used: anti-calretinin (7699/4, Swant, Bellinzona, Switzerland; or a kind gift of Dr B. Schwaller, Fribourg, Switzerland); anti-calbindin D-28k (CB-38, Swant), or anti-parvalbumin (PV-28, Swant); these antibodies were used at dilutions in the range $1: 500-1: 2000$. Simultaneously, a mouse monoclonal anti-Rab3A-antibody (CL 42.2, Synaptic Systems, Göttingen, Germany; or a kind gift of Dr R. Jahn, Göttingen) was co-applied at a dilution of either $1: 500,1: 1000$ or $1: 2000$. In some experiments, a monoclonal antibody against calretinin (M7245, DakoCytomation, Hamburg, Germany; 1 : 200) was used together with the polyclonal anti-parvalbumin antibody. After rinsing three times with PBS and once with BF, the slices were incubated with secondary antibodies diluted $1: 200$ in BF for $2-3 \mathrm{~h}$ at room temperature. Subsequently, slices were kept at $4{ }^{\circ} \mathrm{C}$ overnight. An FITC-coupled secondary anti-rabbit antibody (FI-1000, Vector Laboratories, Burlingame, CA, USA) was used to detect CR, CB and PV immunoreactivity. CY ${ }^{\mathrm{TM}} 5$-conjungated donkey anti-mouse $\mathrm{IgG}$ antibody (715-175-151, Jackson Immunoresearch Laboratories, West Grove, PA, USA) was used to detect the Rab-3A immunoreaction.

\section{Microscopy}

Immunofluorescence images were taken with a confocal microscope (LSM 410 controlled by LSM 3.98 software attached to and Axiovert 135TV, Zeiss). An argon laser for exciting FITC at $488 \mathrm{~nm}$ and a helium-neon laser for exciting CYТ 5 at $633 \mathrm{~nm}$ were used. Emission wavelength was filtered at $515 \mathrm{~nm}$ and $665 \mathrm{~nm}$ for images taken for the FITC and CYTM5 fluorescence, respectively. Magnification was adjusted with the following objectives: $16 \times(0.5 \mathrm{NA}), 40 \times$ oil immersion (1.3 NA) and $63 \times$ oil immersion (1.4 NA) and was further increased by a given zoom-factor (up to eight-fold). Images of $1024 \times 1024$ pixels were taken with 100 -fold reduced laser intensity and averaged $16 \times$ with a sampling time of 8 s per image. All images shown were obtained from single optical sections. Contrast and brightness were adjusted for each individual image to obtain optimal resolution, and therefore no statement about absolute fluorescence or changes in fluorescence intensity can be made between different images.

\section{Data analysis}

Images were imported into IgorPro4.01 (WaveMetrics Inc.), and overlay images were produced with a custom-written IgorProfunction, without further contrast enhancement. For counting the number of CR-positive calyces (Figs 1-3), the overlay images were exported to Adobe Photoshop 6.0, and analysed in a procedure illustrated in Fig. 1A-C (right-hand panels). First, an individual calyx was identified based on its Rab-3A staining, which was apparent either in the single fluorescence image (Fig. 1A, right panel) or as the redcoded signal in the corresponding overlay image (Fig. 1C, right panel). Then, the CR staining of the same calyx was evaluated. For this purpose, we routinely went back to the single fluorescence image at linearly increased contrast and brightness, to also detect calyces dimly stained for CR (see Fig. 1B, right panel, arrow, for an example of a calyx dimly stained for CR). To avoid double-counting of individual calyces, each Rab-3A-positive calyx was marked with a blue dot, and additionally with a white dot if CR immunofluorescence was present (see Fig. 1C, right panel). After analysis of all Rab-3Apositive calyces in a given MNTB section, the Rab-3A-positive calyces and the CR-positive calyces were counted using the blue and white dots in the image, and the percentage of CR-positive calyces was calculated for each section. The mean \pm SEM values for a given species and developmental stage were calculated by averaging over all percentage values of individual sections, with $n$ referring to the number of sections analysed, and $N$ referring to the number of animals for each condition. The sections were analysed in a random sequence, irrespective of their localization with respect to the anterior-posterior axis of the brain.

Line profiles were taken from overlay images with an IgorPro software routine, and were composed of 2-4 pixels in width.

\section{Results \\ Calretinin expression is heterogenous between calyx of Held nerve terminals}

Figure 1 shows a brainstem section on the level of the MNTB of a P33 mouse, double-stained with an antibody against the presynaptic marker protein Rab-3A, and an antibody against CR. In the Rab-3A stain, single calyces of Held are clearly discernible even at low magnification (Fig. 1A, left panel). Here, the entire cross-section of the MNTB is visible, with laminae of calyces interleaved between negatively stained axon bundles that run from medial to lateral through the MNTB. At higher magnification (Fig. 1A, right panel), individual calyces of Held are apparent as circular staining patterns, presumably surrounding the somata of individual MNTB principal cells, which are not visible with the anti-Rab-3A antibody. Double-staining MNTB sections with antibodies against Rab-3A and CB showed that the Rab-3A staining is adjacent to the somata of MNTB principal cells, which express $\mathrm{CB}$ (see below, Fig. 6A). Furthermore, double-stains of MNTB sections with antibodies against $\mathrm{S} 100 \beta$ and Rab-3A confirmed that Rab-3A is located 

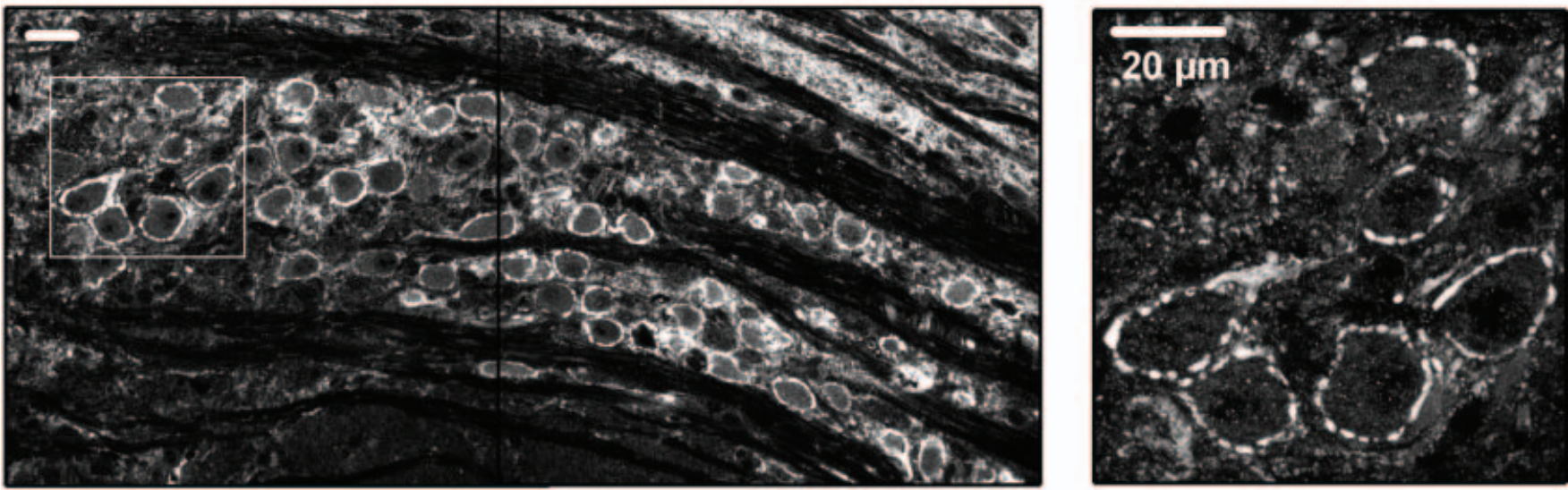

B

Calretinin
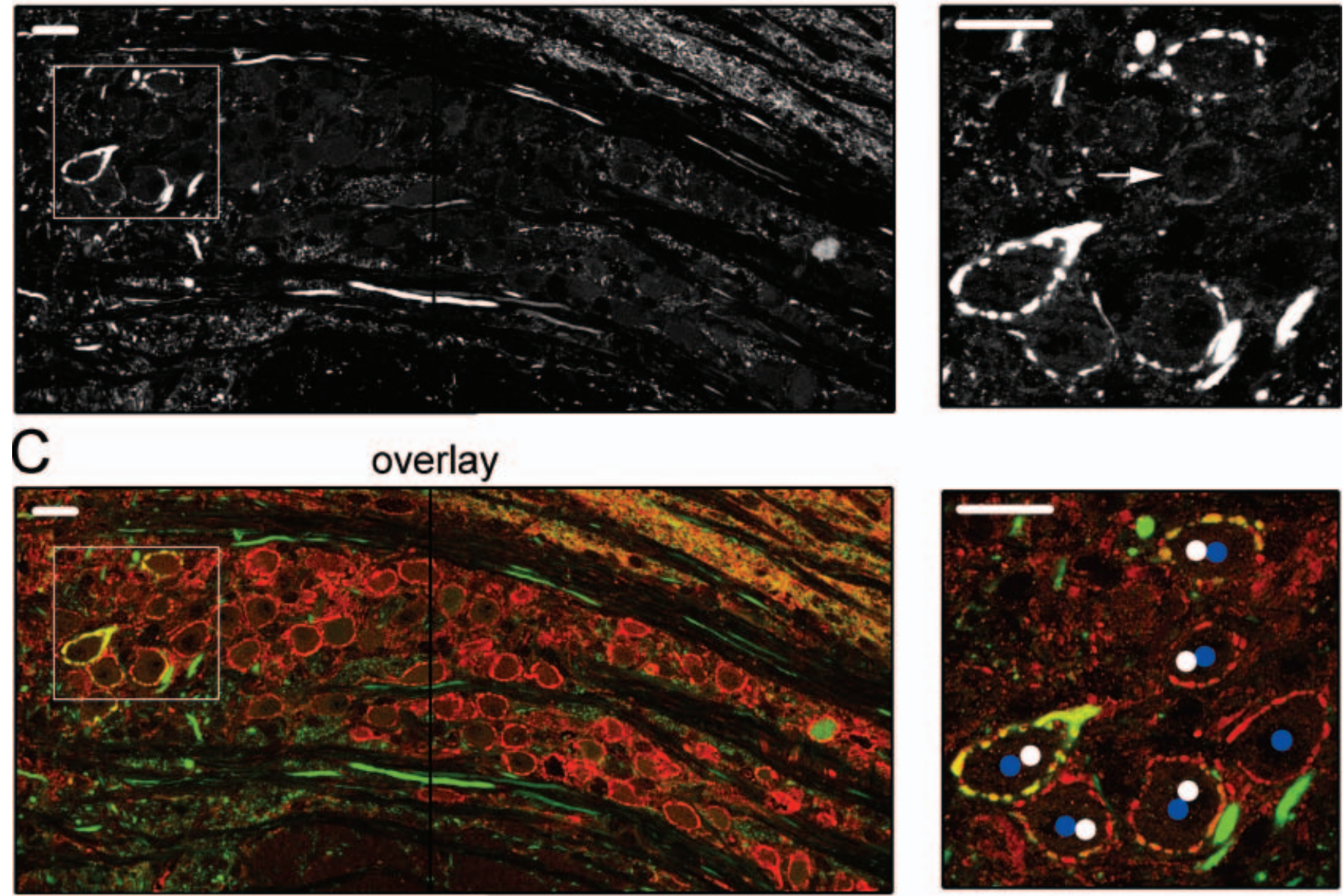

FIG. 1. Calyces of Held are heterogeneous with respect to CR expression. Double immunofluorescence images with primary antibodies against Rab-3A (A) and CR (B) are shown for a section of the MNTB from a P33 mouse. In C, overlay images are shown, with red and green colour corresponding to Rab-3Aand CR-like immunofluorescence, respectively. For each panel, the region indicated by the box is shown at higher magnification on the right. Note that CR-positive calyces of Held are only found in the most lateral part of the MNTB, corresponding to the left sides of the images. The arrow in the right panel of B indicates a calyx dimly stained with the anti-CR antibody. In the right panel of $\mathrm{C}$, the markers that were added during the evaluation of individual calyces are also shown, with blue dots identifying Rab-3A-positive calyces, and white dots identifying CR-positive calyces (see Materials and methods). All scale bars, $20 \mu \mathrm{m}$.

in the nerve terminals, but not in glia cells that are stained by the antiS100 $\beta$ antibody (data not shown).

In Fig. 1B, the staining pattern produced by the anti-CR antibody in the same MNTB section is shown. Some calyces localized in the most lateral portion of the MNTB are clearly stained by the anti-CR antibody, whereas the majority of the remaining Rab-3A-positive calyces were, surprisingly, not stained by the anti-CR antibody. This is also seen in the overlay image (Fig. 1C), in which the fluorescence channels corresponding to the Rab-3A and CR signals are coded in red and green, respectively. A clear overlay of Rab-3A and CR staining 

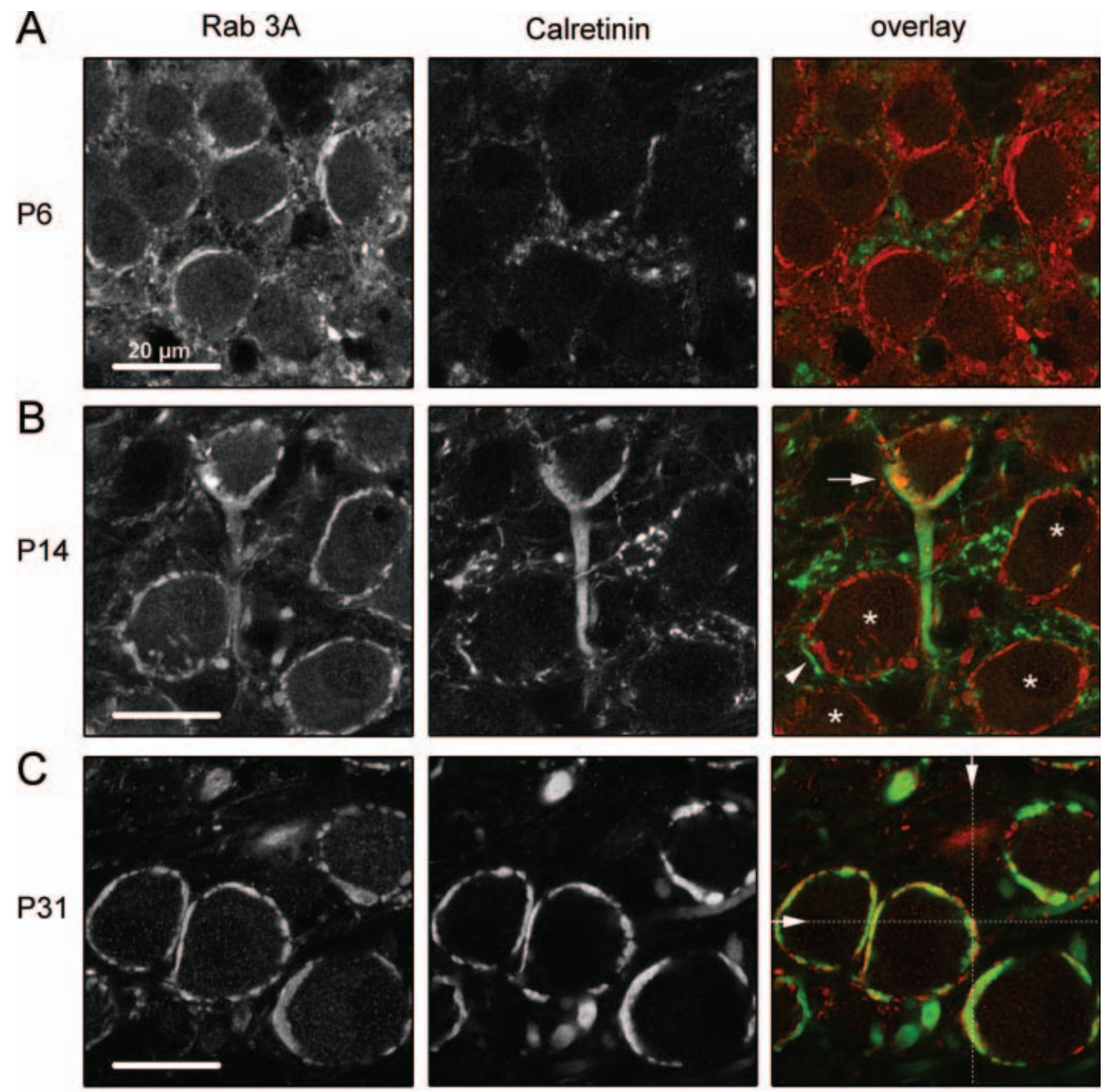

D

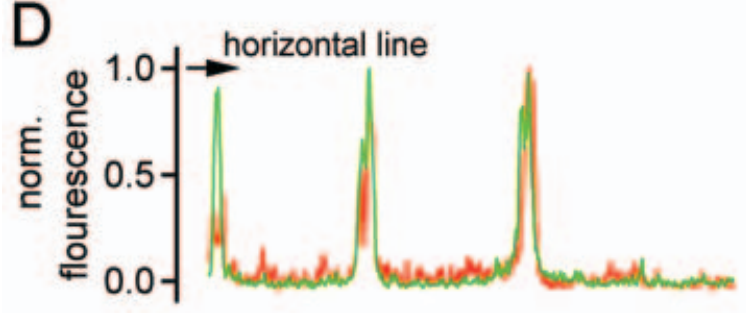

E P31
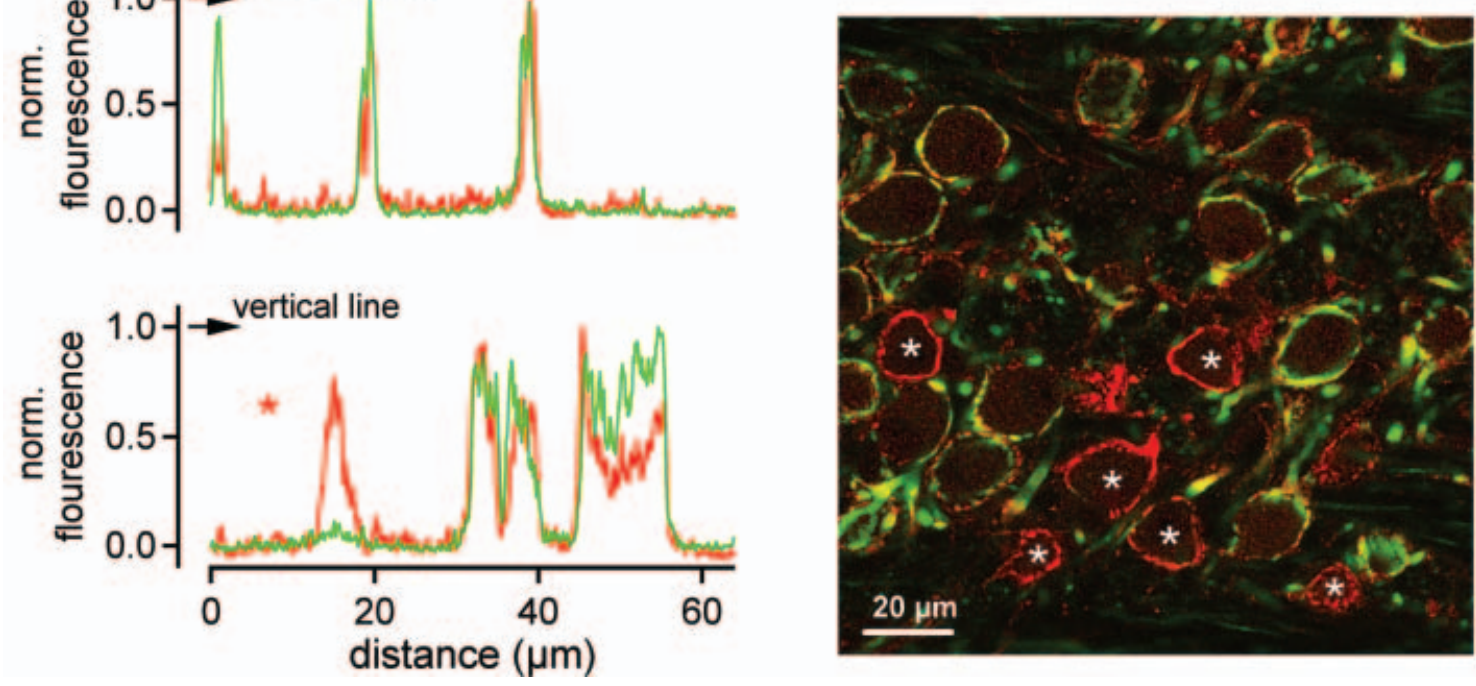


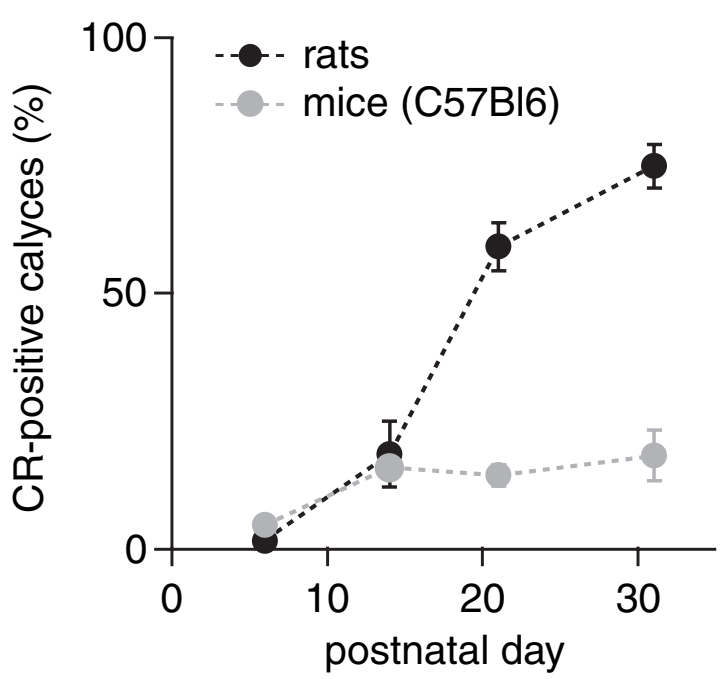

FIG. 3. The percentage of CR-positive calyceal nerve terminals increases during postnatal development, but this developmental increase is different in mice and rats. Calyceal nerve terminals, identified based on the Rab-3A staining pattern, were classified as CR-positive or CR-negative calyces as detailed in the Materials and methods (see also Figs 1 and 2), and the percentage of CR-positive calyces was calculated for each MNTB section. Each data point represents the average \pm SEM value from $n=4-16$ MNTB sections, obtained from $N=3$ (or sometimes 2) animals. The total number of Rab-3Apositive calyces analysed was in the range of 228-375 for each age group in mice, and 413-1075 for each age group in rats. Note that after postnatal day 14, a strong increase in the percentage of CR-positive calyces of Held was observed in rats (black symbols). In mice (grey symbols), the percentage of CR-positive calyces slightly increased up to P14, but later stayed on a rather low level throughout the postnatal period investigated here.

pattern is apparent only for the most lateral calyces. Some CR-positive fibres are also visible, which run within axon bundles where Rab-3A staining was absent (Fig. 1C, left panel). These CR-positive fibres probably correspond to axons that give rise to CR-positive calyces.

The immunofluorescence images in Fig. 1 suggest that in mice, only a small fraction of Rab-3A identified calyces of Held express CR. To quantify the percentage of CR-positive calyces, we analysed higher magnification images of MNTB sections double-stained with anti-CR antibody and anti-Rab-3A antibody (Fig. 1A-C, right panels). The subfield of the MNTB shown in Fig. 1A-C (right panels) corresponds to the most lateral portion of the MNTB of Fig. 1A-C (left panels, squares). In the subfield shown in Fig. 1C (right panel), six calyces of Held were identified based on the Rab-3A staining pattern, and five of these six calyces were CR-positive (see Materials and methods for details of the classification procedure). In the entire MNTB section shown in Fig. 1, only seven out of 64 calyces (11\%) were classified CR-positive. On average, in mice of postnatal day P31, $18 \pm 5 \%$ ( $N=2, n=6$ sections) of all calyces identified by the Rab-3A staining pattern also expressed $\mathrm{CR}$, suggesting a heterogeneity of $\mathrm{CR}$ expression between calyces of Held.

\section{Developmental expression of CR at the calyx of Held}

We next investigated the cellular localization of CR in the MNTB during postnatal development in rats and in mice (Figs 2 and 3). Figure 2 summarizes the results obtained in rats at three out of four postnatal ages studied (P6, P14, P21 and P31). At P6 $(N=3, n=6$ sections), Rab-3A reliably labelled calyces of Held, whereas in the same region CR staining was diffuse, and occurred in the neuropil, but not in the nerve terminals and the principal neurons of the MNTB (Fig. 2A). In fact, the stains for Rab-3A and CR showed no major overlap (Fig. 2A, right panel). At P14 (Fig. 2B, $N=3, n=10$ sections), the $\mathrm{CR}$ antibody sometimes stained calyces in addition to meshwork-like structures in the neuropil (Fig. 2B, right panel, arrowhead). In the overlay, a partial colocalization of CR and Rab3A staining is evident for one calyx in this subfield (Fig. 2B, right panel, arrow). However, the subcellular codistribution of Rab-3A- and CR-like immunofluorescence was not perfect. In this and other examples, the CR-like immunofluorescence also covered axonal regions attached to the calyx, which were not stained by the antiRab-3A antibody (Fig. 2B, right panel, arrowhead). In the calyceal region, the $\mathrm{CR}$ staining pattern was broader than the more confined Rab-3A staining (Fig. 2B, right panel). In addition to some calyces that showed CR expression, most calyces were clearly devoid of CRlike immunofluorescence at this developmental stage (P14; see Fig. 2B, right panel, asterisks).

In Fig. 2C, an immunocytochemical double-stain against Rab-3A and CR is illustrated for a P31 rat. CR staining of calyx-like nerve terminals was prominent, and in the overlay both markers matched to a large extent (Fig. 2C, right panel). Individual calyces seemed fenestrated, a typical feature for the calyx of Held in rats older than about P14 (Kandler \& Friauf, 1993; Taschenberger et al., 2002). Stained cytoplasmic regions and nonstained gaps probably caused by fenestration corresponded between the Rab-3A stains and the CR stains (Fig. 2C, left and middle panel). To verify the extent of colocalization, we took line profiles (Fig. 2D) along the horizontal and vertical dotted lines in the overlay image (Fig. 2C, right panel). The normalized fluorescence intensity of both immunoreactivities had similar spatial profiles, except for one position of preferential Rab-3A localization in the vertical line (see asterisk in Fig. 2D).

Despite the prominent expression of CR in many rat calyces at P31 (Fig. 2C), we observed that not all Rab-3A-labelled calyces were CR-positive, as was found in mice (Fig. 1). Figure 2E shows a doublestain with anti-Rab-3A antibody (red) and anti-CR antibody (green) in a P31 rat at lower magnification. CR-negative calyces are clearly identified (see asterisks in Fig. 2E). We found that the percentage of CR-positive calyces, analysed as detailed in Materials and methods, increased during postnatal maturation in rats and mice (Fig. 3). In both species, the percentage of CR-containing calyces was below $5 \%$ at P6, and increased to $18 \pm 6 \%(N=3, n=10$ sections $)$ and $16 \pm 1 \%$ ( $N=3, n=4$ sections) at P14 in rats and mice, respectively. With further maturation, the percentage of $\mathrm{CR}$-containing calyces further increased in rats, to $74 \pm 4 \%$ at $\mathrm{P} 31$ ( $N=3, n=16$ sections; see

FIG. 2. Developmental expression of CR at the rat calyx of Held. (A-C) Double immunocytochemistry with an anti-Rab-3A antibody, and an anti-CR antibody. MNTB sections from rats at three postnatal ages (P6, P14 and P31) are shown. The left and middle panels show the immunofluorescence images for the Rab-3A and $\mathrm{CR}$ stains, and the right panels present the corresponding overlay images, with red and green colour corresponding to Rab-3A- and CR-like immunofluorescence, respectively. The arrow in the right panel of B identifies partially overlapping staining pattern of Rab-3A and CR-like immunofluorescence, and the arrowhead points to meshwork-like CR staining in the neuropil of the MNTB, which sometimes was closely adjacent to Rab-3A-labelled calyceal nerve terminals. The asterisks in the right panel of B identify calyces classified as CR-negative. (D) Line profiles taken from the overlay image shown in the right panel of C, with the position and direction of the lines as indicated in C. Green and red lines correspond to the CR- and Rab-3A fluorescence intensity, respectively. The asterisk in the lower panel of $\mathrm{D}$ identifies a Rab-3A-stained spot at which CR -staining was weak. In E, an overlay image of Rab-3A-like immunofluorescence (red) and CR-like immunofluorescence (green) is shown for an MNTB section from a P31 rat. Calyces classified as CR-negative are marked by white asterisks. All scale bars, $20 \mu \mathrm{m}$. 


\section{A PV}

P6

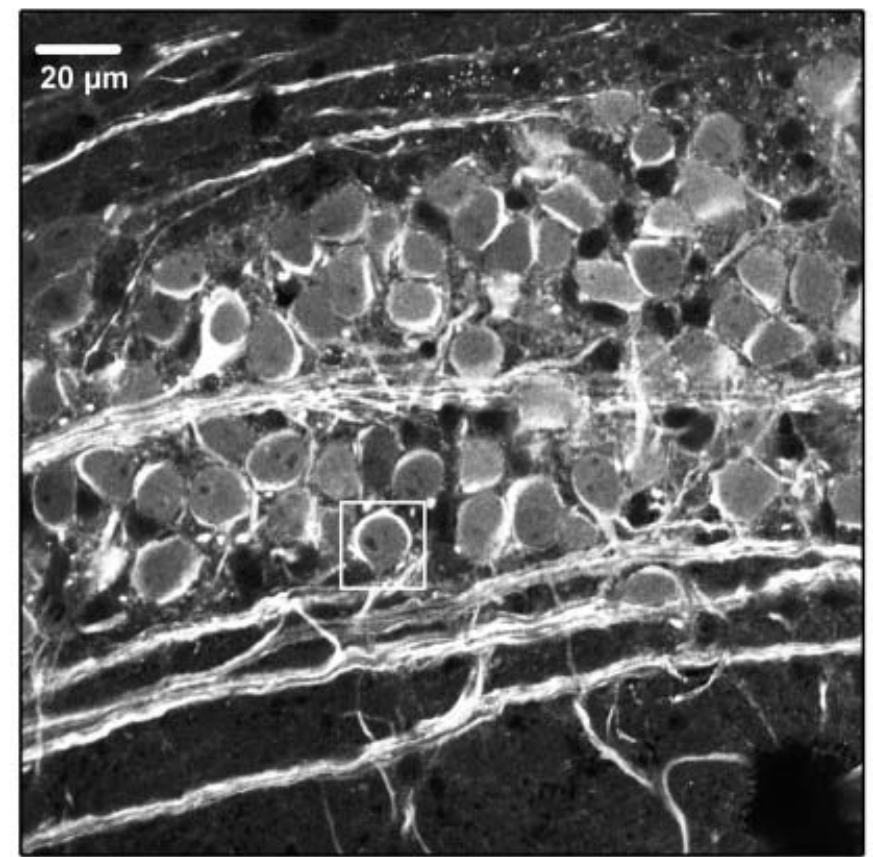

C PV

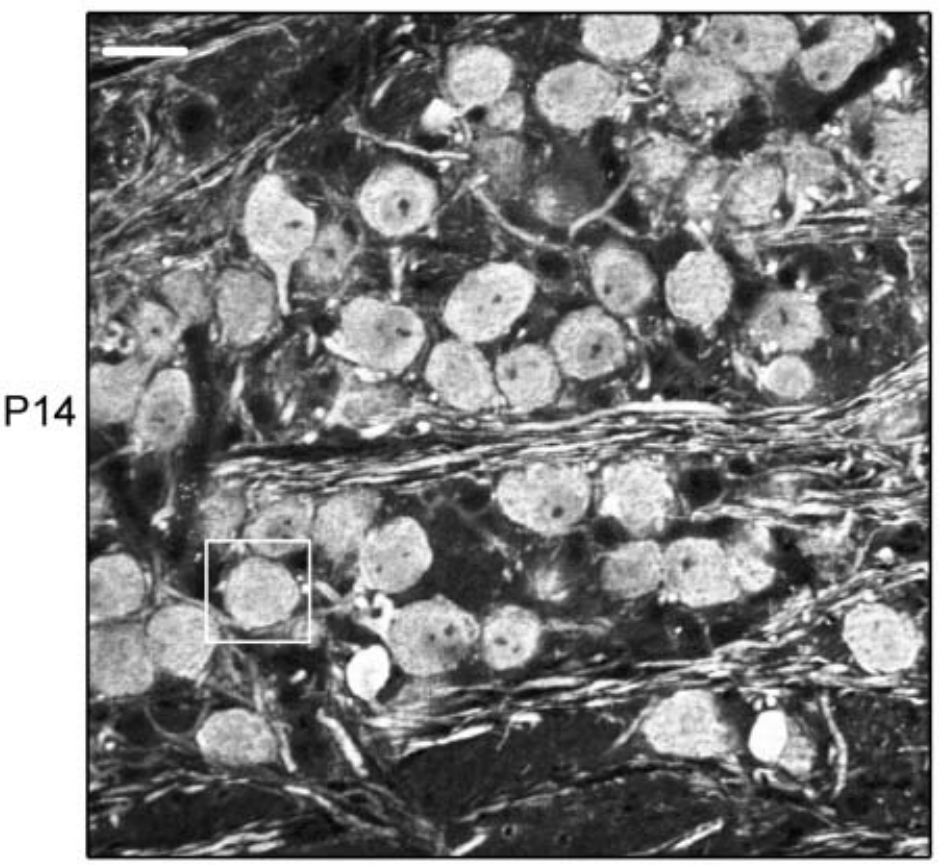

B PV

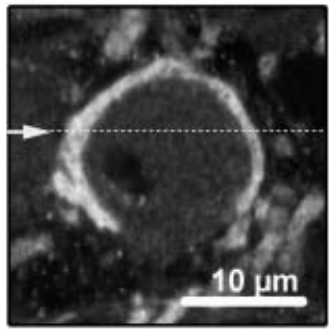

Rab-3A
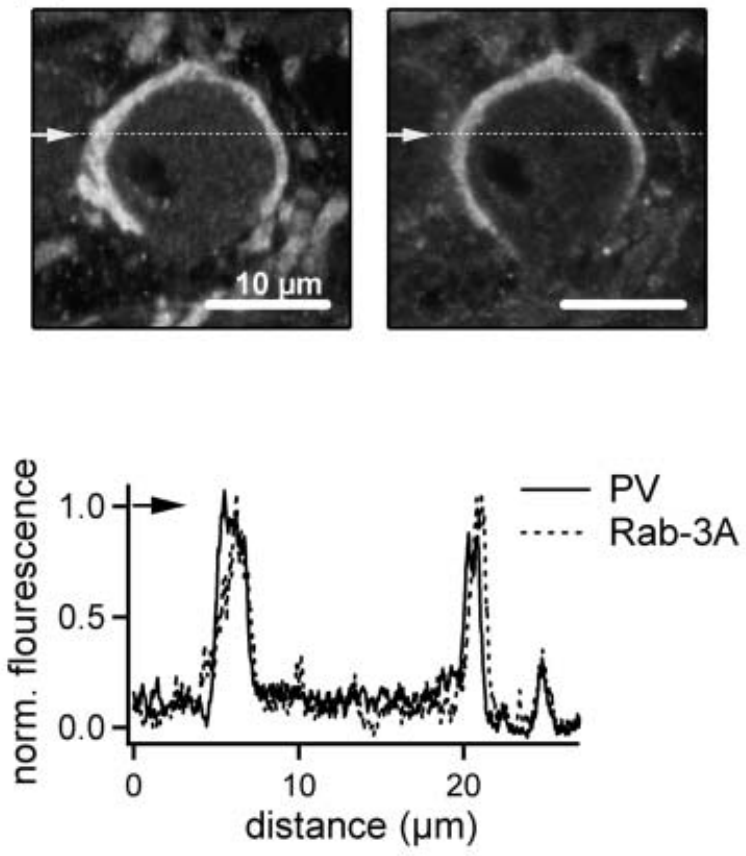

D PV

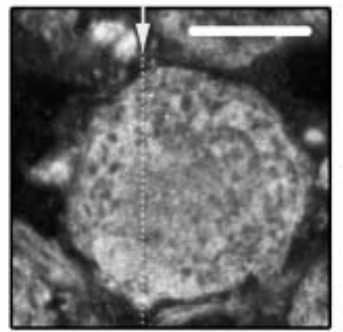

Rab-3A
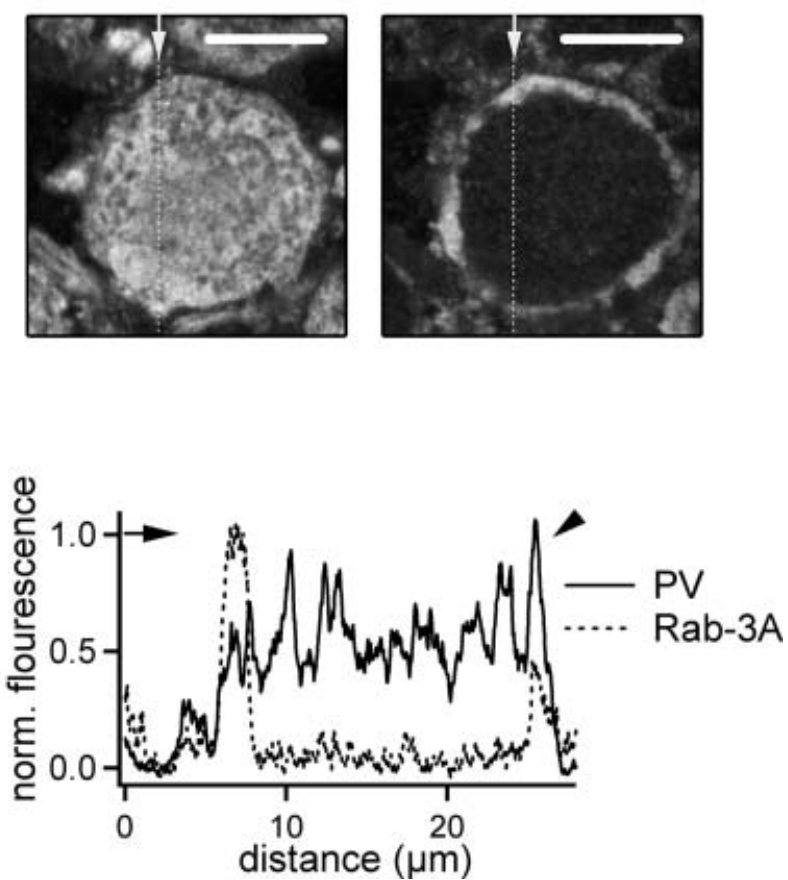

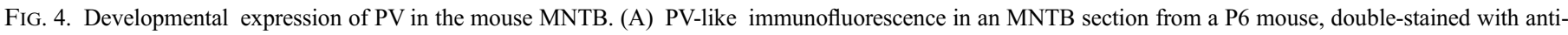

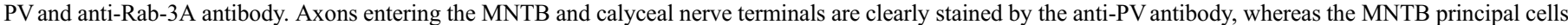

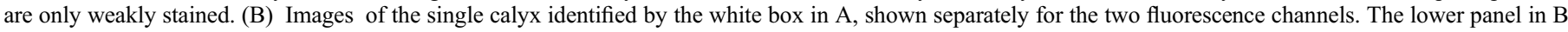

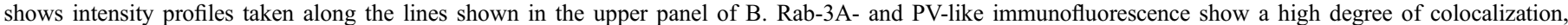

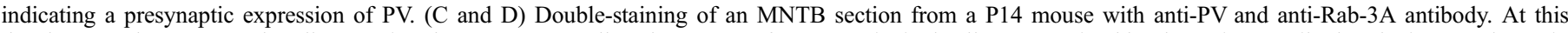

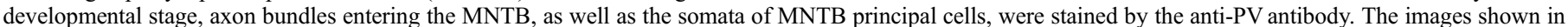

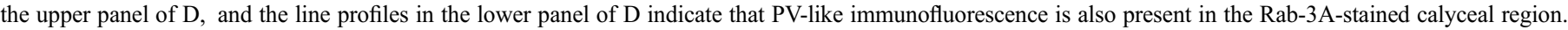

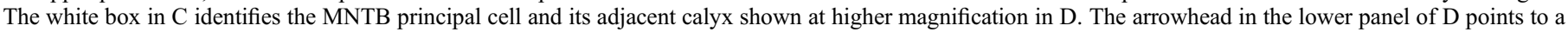
PV-like immunofluorescence signal present in the calyceal region. Scale bars, $20 \mu \mathrm{m}$ (A and C), and $10 \mu \mathrm{m}(\mathrm{B}$ and $\mathrm{D})$. 
Fig. 3). In mice, however, the number of CR-positive calyces stayed at the same low level, reaching $18 \pm 5 \%(N=2, n=6$ sections $)$ at $\mathrm{P} 31$ (see Figs $1 \mathrm{~B}$ and $\mathrm{C}$, and 3 ). Thus, during postnatal maturation, an increasing number of calyces express $\mathrm{CR}$, but the exact percentage of CR-positive calyces is different between rats and mice (Fig. 3). The heterogenous expression of $\mathrm{CR}$ between calyces might cause differences in $\mathrm{Ca}^{2+}$ signalling and transmitter release probability between calyces (see Discussion).

\section{Parvalbumin is expressed in calyces of Held}

Parvalbumin, an EF-hand CaBP with slow $\mathrm{Ca}^{2+}$-binding kinetics (Lee et al., 2000), has been shown to be present in the somata of MNTB principal cells (Caicedo et al., 1996; Lohmann \& Friauf, 1996). In addition to its postsynaptic localization, we found that PV is also present in the presynaptic calyces of Held. This is most clearly seen in the developmental series taken from mice (Fig. 4). Early in postnatal development (P6; Fig. 4A), the anti-PV antibody selectively stained the fibres of the trapezoid body, and the presynaptic calyces that surround weakly stained somata of the MNTB principal cells. Figure 4B shows a single calyx at higher magnification for both fluorescence channels. These images, and the corresponding line profiles (Fig. 4B, lower panel) illustrate a high degree of colocalization between the PV and the Rab-3A immunoreactivity, indicating that PV is present at calyces of Held of neonatal mice.

At postnatal day P14, the principal cells of mice MNTB were also strongly stained by the anti-PV antibody (Fig. 4C). To distinguish between the postsynaptic and the presynaptic localization of PV, we made line profiles through somatic and calyceal regions of PV and Rab-3A double-stains (Fig. 4D). This shows that the PV-like fluorescence signal (continuous trace) extends into the presynaptic region, which is labelled by the anti-Rab-3A antibody (dotted line; Fig. 4D, lower panel). Thus, at P14, PV is present in the postsynaptic principal cells of the MNTB (Lohmann \& Friauf, 1996), as well as in the presynaptic calyces of Held. The presence of PV in calyces of Held at this developmental stage is corroborated by the finding that the axon bundles traversing the MNTB are clearly labelled by the anti-PV antibody (Fig. 4C). Similar observations as in P14 mice $(N=2)$ were made in mice of postnatal day P21 $(N=2)$ and P31 $(N=1)$.

In rats, we found that the presynaptic calyceal region as well as the somata of the postsynaptic principal cells were labelled by the anti-PV antibody, at all developmental stages investigated here (P8-P33). Figure 5A shows a double-stain for PV and Rab-3A of an MNTB region in a P10 rat. Careful inspection of these images revealed a PV-like fluorescence signal close to the edge of the principal cell somata, in regions which are also stained by the Rab-3A antibody (Fig. 5A, middle and left panel). This is confirmed in the overlay of Rab-3A and PV stains in Fig. 5A (right panel). The line profiles in Fig. 5B also suggest that $\mathrm{PV}$ is present presynaptically. The horizontal line in Fig. 5A (right panel) passes through two adjacent MNTB principal cells, with their two calyces separated by a small gap (see Fig. 5A, right panel). The corresponding line profile shows that the width of the gap is identical for the Rab-3A- and the PV-like immunofluorescence (Fig. 5B, left panel, arrowhead), indicating that $\mathrm{PV}$ is present in the presynaptic regions immediately adjacent to the gap. Similarly, in the vertical line profile, the PV-like immunofluorescence extended into the presynaptic calyx region, which was stained by the anti-Rab-3A antibody (Fig. 5B, right panel, arrowhead). Thus, similarly as in mice, $\mathrm{PV}$ is localized in the presynaptic calyces of Held, as well as in the principal cell somata of the MNTB. The presynaptic localization of $\mathrm{PV}$ in rats is also corroborated by the finding that the anti-PV antibody strongly stained the presynaptic fibre bundles that enter the MNTB (data not shown; see also Lohmann \& Friauf, 1996). We sometimes observed calyceal regions identified by the Rab-3A-like immunofluorescence, which seemed to be devoid of PV-like immunofluorescence. However, the strong simultaneous labelling of the somata of the principal cells precluded a detailed quantification of the percentage of calyces of Held that expressed PV.

Finally, we investigated the distribution of CB in the MNTB of rats between P6 and P30 (Fig. 6). Figure 6A shows a CB-Rab-3A doublestain from an MNTB section of a P10 rat at higher magnification, and the corresponding line profiles. CB-like immunofluorescence was clearly present in the somata of MNTB principal cells (Friauf, 1993; Caicedo et al., 1996), but it did not extend into the Rab-3A-positive calyx-like region (Fig. 6A and B). Similar observations were made in $n=34$ MNTB slices, at all ages tested (P6-P33). We also quantified the percentage of MNTB principal cells that expressed CB. At P6 and P8, $87 \pm 3.3 \%(N=4, n=8$ sections $)$ of all CB-positive somata were surrounded by Rab-3A-labelled calyceal nerve terminals. From $\mathrm{P} 10$ to $\mathrm{P} 31$, this percentage increased to nearly $100 \%$ (P10: $98 \pm 3 \%$, $N=4, n=5$ sections; P31: $97 \pm 11 \%, N=3, n=8$ sections). Thus, after about $\mathrm{P} 10$, the population of CB-expressing MNTB neurons is essentially identical with the neurons that receive a calyx-like, Rab3Apositive synaptic terminal. In conclusion, $\mathrm{CB}$ is probably expressed by all MNTB principal cells, but it is not detectable in the calyx of Held nerve terminals.

\section{Discussion}

We investigated the developmental expression of three EF-hand CaBP, $\mathrm{CR}, \mathrm{CB}$ and PV, in the MNTB, with emphasis on the localization of CaBPs in the large nerve terminals innervating the MNTB principal cells, the calyces of Held. To discriminate between the pre- and postsynaptic localization, we used confocal microscopy and twocolour immunofluorescence imaging with primary antibodies detecting Rab-3A, a presynaptic marker protein, and one of the three CaBPs investigated here.

It is known that CR is strongly expressed in neurons of the auditory system. Specifically, the auditory fibres and various neuronal populations in the cochlear nucleus express high densities of CR (Arai et al., 1991; Resibois \& Rogers, 1992; Caicedo et al., 1996; Lohmann \& Friauf, 1996), and neurons in the globular cell area, corresponding to region II of the anterior ventral cochlear nucleus of Harrison \& Irving (1965), were strongly labelled by anti-CR antibody (Resibois \& Rogers, 1992). Calyces of Held arise from globular bushy cells in the aVCN (in rats and mice: Harrison \& Irving, 1966; Friauf \& Ostwald, 1988; Kuwabara et al., 1991; in cats: Spirou et al., 1990, and references therein). One would therefore expect that calyces of Held contain CR, and indeed, CR-positive calyces of Held, surrounding CR-negative somata of the MNTB, have been repeatedly observed in adult rats or guinea-pigs (Arai et al., 1991; Resibois \& Rogers, 1992; Caicedo et al., 1996; Lohmann \& Friauf, 1996). Here we confirm that CR expression in the MNTB was restricted to the presynaptic calyces (Figs 1 and 2). Surprisingly, however, we found that CR was not expressed in all calyces of a given MNTB section (Figs 1-3). In mice, CR-positive calyces were preferentially found at the lateral end of the MNTB in transverse slices (Fig. 1B and C). This localization corresponds to the low-frequency end of the tonotopically organized MNTB as investigated in rats (Friauf, 1992; Saint Marie et al., 1999) and other mammalian species (Guinan et al., 1972). In rats, however, CR-negative calyces were randomly interspersed between CR-expressing calyces of Held, without apparent preference along the lateral- 

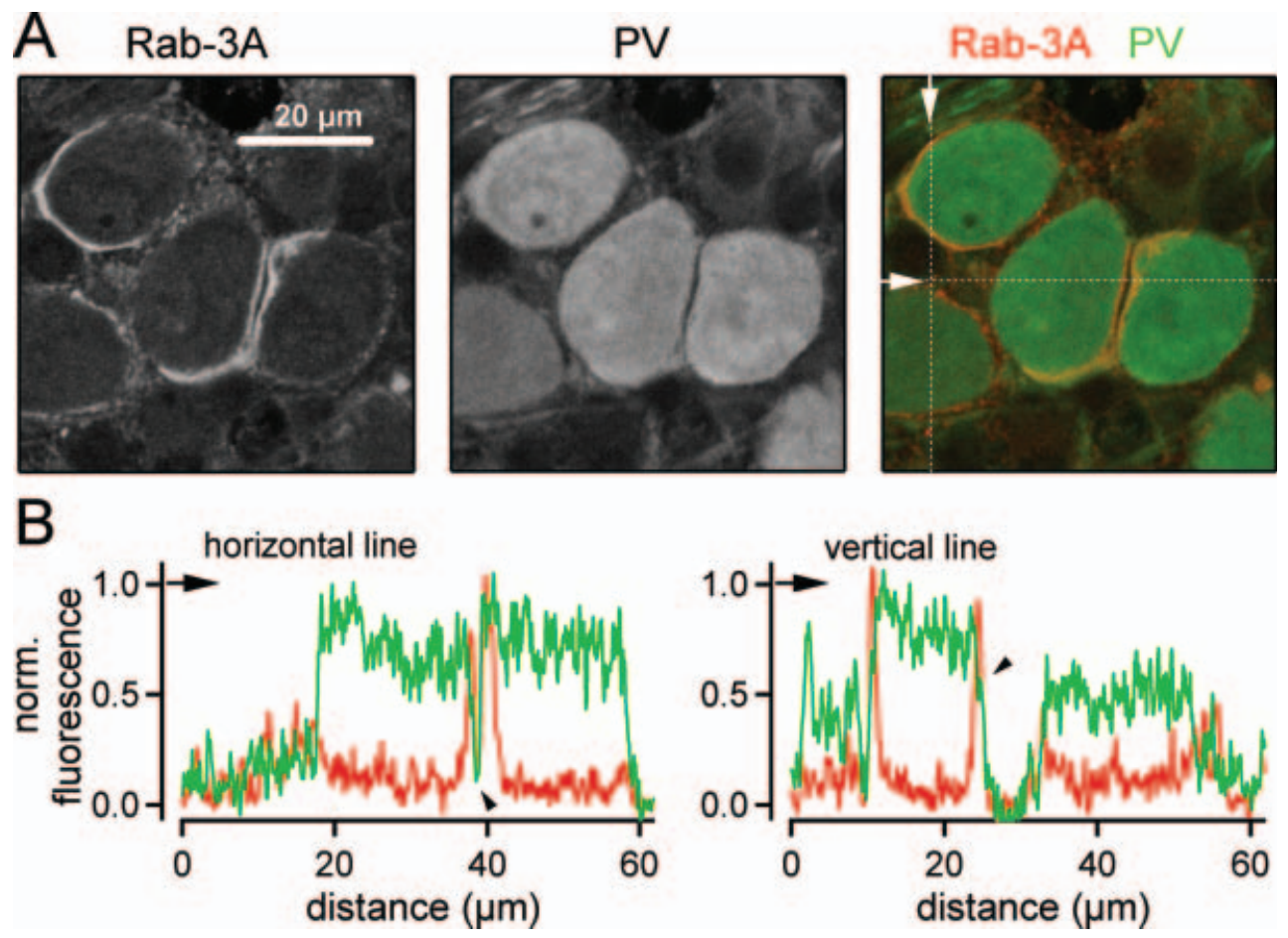

FIG. 5. PV is expressed in the calyx of Held nerve terminals, as well as in the principal cell of the rat MNTB. Results from a double-labelled MNTB section from a P10 rat, incubated with anti Rab-3A and anti-PV antibodies, are shown. (A) Calyces of Held stained with the anti-Rab-3A antibody (left panel), and principal cell somata stained with the anti-PV antibody (middle panel) are clearly identified. The overlay image (right panel) shows that PV-like immunofluorescence is also present in the Rab-3A-labelled calyceal nerve terminals. (B) Line profiles along the horizontal (left panel) and vertical (right panel) lines indicated in the overlay image (A, right panel). Note that the PV-like immunofluorescence clearly extends into the presynaptic, Rab-3A-positive regions (arrowheads). The green and red lines indicate PV-like and Rab-3A-like immunofluorescence, respectively.
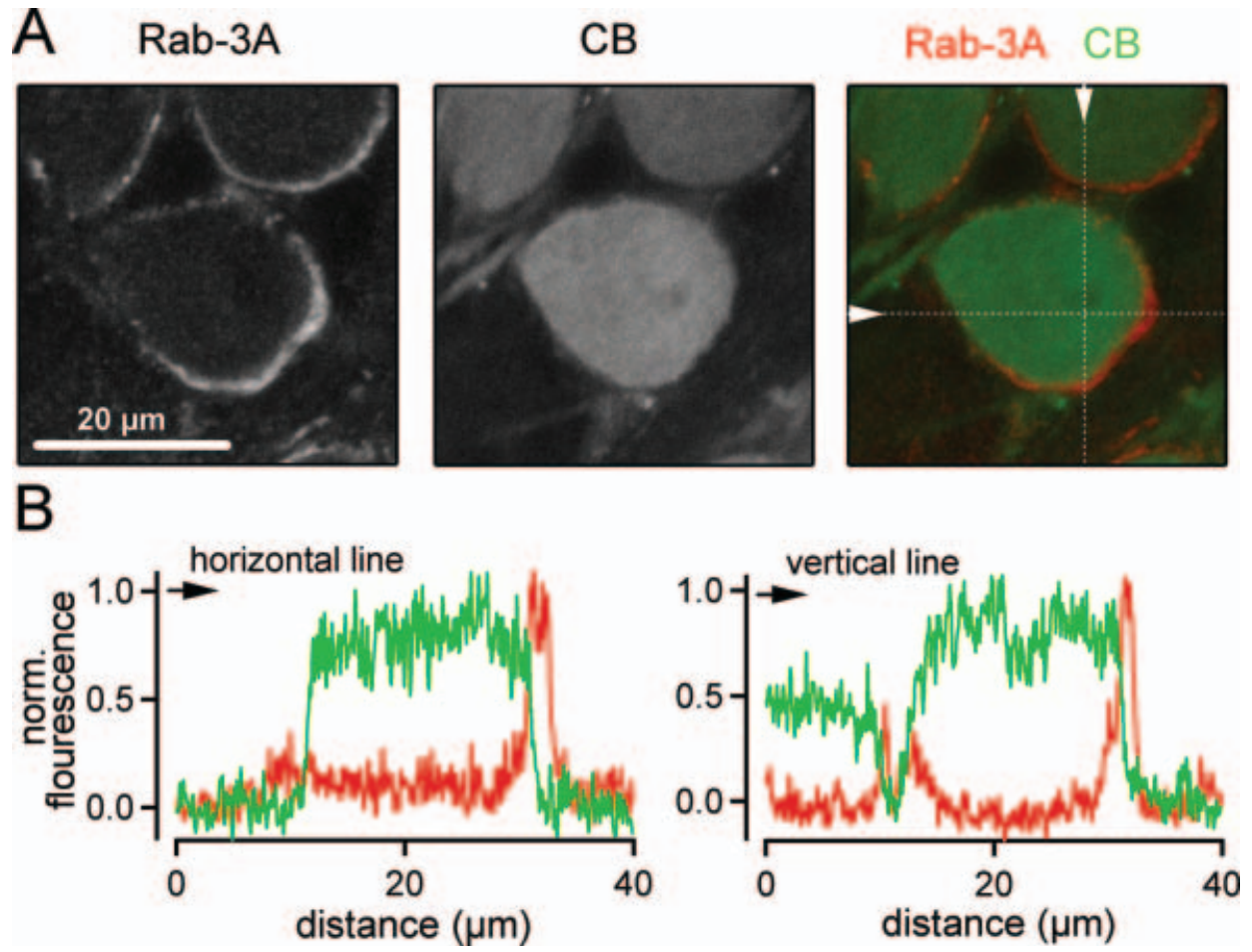

FIG. 6. Calbindin D-28k (CB) expression in the MNTB is restricted to the postsynaptic principal cells. Results from double-labelling of an MNTB section from a P10 rat, incubated with anti Rab-3A and anti-CB antibodies, are shown. (A) Calyces of Held stained with the anti-Rab-3A antibody (left panel) and principal cell somata stained with the anti-CB antibody (middle panel). The overlay image (right panel) suggests that the CB-like immunofluorescence does not extend into the presynaptic, Rab-3A-labelled compartment. (B) Line profiles of the normalized fluorescence intensities of Rab-3A-like immunoreactivity (red trace) and CB-like immunoreactivity (green trace). Note that when the Rab-3A-like immunofluorescence signal increases, the CB-like fluorescence signal decreases, suggesting that CB is localized exclusively to the somata of MNTB principal cells. The position and direction of these line profiles are indicated by the lines superimposed onto the overlay image in the right panel of A. 
medial axis in transverse slices of the MNTB (Fig. 2E). Therefore, a species-specific difference with respect to the distribution of CR-positive calyces in the MNTB of mice and rats is apparent. Whether the distribution of CR-positive calyces in the MNTB of mice subserves a specific role in the localization of low- vs. high-frequency sounds has yet to be determined.

The finding that many calyx of Held nerve terminals do not contain a detectable signal in immunocytochemistry with the anti-CR antibody suggests a heterogeneity in terms of CR expression between globular bushy cells of the aVCN from which calyces of Held arise. In additional immunocytochemical stains using a monoclonal antibody against CR (see Materials and methods), we confirmed that only a small fraction ( $\sim 15 \%$ or less) of all calyces of P20-P30 C57B16 mice were CR-positive, thus ruling out a simple artefact as a cause of the heterogeneity of CR expression between calyces. In our analysis, we classified calyces as CR-positive and CR-negative based on visual inspection of high-resolution, confocal immunofluorescence images (Figs 1 and 2). We cannot exclude that calyces classified as CRnegative contain $\mathrm{CR}$, albeit at a significantly lower concentration. Irrespective of this possibility, our data indicate a strong heterogeneity of calyces of Held with respect to their CR content. The low percentage of CR-positive calyces in mice up to P31 imposes a serious limitation for a functional analysis of CR knock-out mice (Schurmans et al., 1997) at the calyx of Held.

During postnatal development, the percentage of CR-containing calyces increased (Fig. 3). A significant amount of CR-positive calyces appeared from about P14 onwards, but this developmental increase was different between mice and rats (Fig. 3). The quite late onset of CR expression contrasts with $\mathrm{PV}$, which is present in calyces of Held already at P6, the earliest developmental stage studied here (Fig. 4A and B). PV continues to be present also at later stages in the calyces of Held (up to P31 as investigated here), and it is also expressed in the MNTB principal cells. This developmental expression sequence of $\mathrm{CR}$ and $\mathrm{PV}$ in the MNTB suggests that between P6 and P14, PV is present presynaptically, but CR is absent from a large majority of calyces of Held in both mice and rats. At around P14, coinciding with the onset of hearing in rodents at around P12 (Jewett \& Romano, 1972; Blatchley et al., 1987), the number of CR-positive calyces begins to increase strongly in rats (Fig. 3), suggesting that $\mathrm{CR}$ might become a predominant $\mathrm{Ca}^{2+}$ buffer at most calyces of Held during the third postnatal week. In parallel with the increase in the number of CR-positive calyces, CR became more closely colocalized with the Rab-3A staining during the period of postnatal maturation (P14-P30; see Fig. 2B and C), indicating a presynaptic signalling role for $\mathrm{CR}$. In contrast, $\mathrm{CB}$ was expressed in the somata of MNTB principal neurons (Celio, 1990; Webster et al., 1990; Rogers \& Resibois, 1992; Lohmann \& Friauf, 1996), but we could not detect $\mathrm{CB}$ in the Rab-3a-labelled presynaptic compartment in the MNTB of rats and mice (Fig. 6). Thus CB will not contribute to presynaptic $\mathrm{Ca}^{2+}$-buffering in the calyx of Held.

What might be the consequences of the developmental expression of $\mathrm{CR}$ and $\mathrm{PV}$ for presynaptic $\mathrm{Ca}^{2+}$ signalling and transmitter release at the calyx of Held? Before the onset of hearing at around P12, CR is largely absent from most calyces (Fig. 3). This corresponds well with the finding that the endogenous $\mathrm{Ca}^{2+}$ buffering capacity $\left(\kappa_{\mathrm{s}}\right)$ is quite low at rat calyces of Held at P8-P10 ( $\kappa_{\mathrm{s}} \sim 30$; Helmchen et al., 1997); and this value is among the lowest as compared with various neurons and neuroendocrine cells (Lips \& Keller, 1998; see their table 1). It has also been reported that the endogenous $\mathrm{Ca}^{2+}$ buffering capacity is higher in rat calyces of Held at P11 than at P6 (Chuhma et al., 2001), indicating a possible developmental increase in the presynaptic $\mathrm{Ca}^{2+}$ buffering capacity. If $\mathrm{CR}$ indeed becomes a predominant intracellular
$\mathrm{Ca}^{2+}$ buffer at the rat calyx of Held during postnatal maturation, then we would expect that the average $\kappa_{\mathrm{s}}$ between calyces continues to rise after P14 (see Fig. 3), but that $\kappa_{\mathrm{s}}$ is rather heterogeneous between neighbouring calyces (Figs 1-3). Interestingly, the decay kinetics of $\left[\mathrm{Ca}^{2+}\right]_{\mathrm{i}}$ in calyces of Held was found to be quite variable between cells (Felmy et al., 2003), indicating either a heterogeneity in the expression of rapidly equilibrating $\mathrm{Ca}^{2+}$ buffers and/or a heterogeneity in the $\mathrm{Ca}^{2+}$ extrusion rate between calyces. However, the $\mathrm{Ca}^{2+}$ buffering properties of mature calyces of Held older than P14 have yet to be determined. In addition, the role of $\mathrm{PV}$ as a presynaptic $\mathrm{Ca}^{2+}$ buffer at calyces of Held of young mice or rats before the onset of hearing needs to be addressed.

Glutamatergic synaptic transmission at the calyx of Held undergoes characteristic developmental changes around the onset of hearing (Taschenberger \& von Gersdorff, 2000; Iwasaki \& Takahashi, 2001; Joshi \& Wang, 2002). Among these, transmitter release probability becomes reduced, whereas the apparent size of the readily releasable pool of vesicles increases with development. Together, these changes reduce the amount of synaptic depression, and 'equalize' the first EPSC in comparison with the subsequent EPSCs in response to a train of presynaptic action potentials. Such a developmental 'equalizing' effect contributes to preserving the exact timing between pre- and postsynaptic action potentials during repetitive activity at the calyx of Held synapse (Taschenberger \& von Gersdorff, 2000), and preservation of action potential timing at the calyx of Held synapse is considered relevant for sound source localization (Grothe, 2003). It is tempting to speculate that an increase in CR expression in calyces of Held contributes to this 'equalizing' effect. If $\mathrm{CR}$ is present at sufficiently high intracellular concentrations, it will bind some fraction of the incoming $\mathrm{Ca}^{2+}$ ions before these reach the $\mathrm{Ca}^{2+}$ sensor for vesicle fusion. In this way, CR would decrease the release probability during a first action potential. During trains of presynaptic action potentials, partial saturation of CR would successively reduce the buffering power of $\mathrm{CR}$, leading to an increased effectiveness of residual $\mathrm{Ca}^{2+}$ in inducing synaptic facilitation (Felmy et al., 2003), and counteracting the effects of synaptic depression. Nevertheless, such a role of $\mathrm{CR}$ as a saturable $\mathrm{Ca}^{2+}$ buffer in calyces of Held still needs to be established. From experiments in P8-P10 rats, Felmy et al. (2003) postulated a role for a (so far unidentified) $\mathrm{Ca}^{2+}$ buffer in facilitation at the calyx of Held. However, given the quite late onset of CR expression at around P10-P14 at the calyx of Held (Figs 2 and 3), it is unlikely that CR plays a major functional role at P8-P10.

Taken together, we find that the percentage of calyces expressing $\mathrm{CR}$ is developmentally up-regulated, with a marked heterogeneity of CR expression between calyces of Held. In addition to CR, PV labelling is also observed in nerve terminals, adding a second $\mathrm{CaBP}$ to the presynaptic compartment of this excitatory glutamatergic synapse. The implications for presynaptic $\mathrm{Ca}^{2+}$ signalling and transmitter release are not easily predicted, because a slow and a fast $\mathrm{Ca}^{2+}$ buffer may exert antagonistic effects on short-term facilitation (Caillard et al., 2000; Blatow et al., 2003). Further studies combining immunofluorescence and electrophysiological recordings might clarify how CR and PV together influence short-term synaptic plasticity at the calyx of Held.

\section{Acknowledgements}

We would like to thank Erwin Neher for encouragement and continuous support, Sigrid Schmidt for expert technical assistance with immunocytochemistry and Markus Wölfel for help with analysis routines. We thank Dr Serge Schiffmann and Dr Beat Schwaller for comments on the experimental approach, and Dr Beat Schwaller and Dr Reinhard Jahn for the generous gift 
of antibodies. This work was supported by grants from the Deutsche Forschungsgemeinschaft (DFG; SFB-406 and Schn 451/4-1). R.S. is a Heisenberg fellow of the DFG.

\section{Abbreviations}

aVCN, anterior ventral cochlear nucleus; $\mathrm{CaBP}, \mathrm{Ca}^{2+}$-binding protein; $\mathrm{CB}$, calbindin D-28k; CR, calretinin; MNTB, medial nucleus of the trapezoid body; PV, parvalbumin.

\section{References}

Airaksinen, M.S., Eilers, J., Garaschuk, O., Thoenen, H., Konnerth, A. \& Meyer, M. (1997) Ataxia and altered dendritic calcium signaling in mice carrying a targeted null mutation of the calbindin D28k gene. Proc. Natl Acad. Sci. USA, 94, 1488-1493.

Arai, R., Winsky, L., Arai, M. \& Jacobowitz, D.M. (1991) Immunohistochemical localization of Calretinin in the rat hindbrain. J. Comp. Neurol., 310, 21-44.

Atluri, P.P. \& Regehr, W.G. (1996) Determinants of the time course of facilitation at the granule cell to purkinje cell synapse. J. Neurosci., 16, 5661-5671.

Blatchley, B.J., Cooper, W.A. \& Coleman, J.R. (1987) Development of auditory brainstem response to tone pip stimuli in the rat. Brain Res., 429, $75-84$.

Blatow, M., Caputi, A., Burnashev, N., Monyer, H. \& Rozov, A. (2003) $\mathrm{Ca}^{2+}$ buffer saturation underlies paired pulse facilitation in Calbindin-D28kcontaining terminals. Neuron, 38, 79-88.

Borst, J.G.G., Helmchen, F. \& Sakmann, B. (1995) Pre- and postsynaptic whole-cell recordings in the medial nucleus of the trapezoid body of the rat. J. Physiol. (Lond.), 489, 825-840.

Caicedo, A., d'Aldin, C., Puel, J.-L. \& Eybalin, M. (1996) Distribution of calcium-binding protein immunoreactivities in the guinea pig auditory brainstem. Anat. Embryol., 194, 465-487.

Caillard, O., Moreno, H., Schwaller, B., Llano, I., Celio, M.R. \& Marty, A. (2000) Role of the calcium-binding protein parvalbumin in short-term synaptic plasticity. Proc. Natl Acad. Sci. USA, 97, 13372-13377.

Celio, M.R. (1990) Calbindin D-28k and parvalbumin in the rat nervous system. Neuroscience, 35, 375-475.

Chuhma, N., Koyano, K. \& Ohmori, H. (2001) Synchronisation of neurotransmitter release during postnatal development in a calyceal presynaptic terminal of rat. J. Physiol. (Lond.), 530, 93-104.

Edmonds, B., Reyes, R., Schwaller, B. \& Roberts, W.M. (2000) Calretinin modifies presynaptic calcium signaling in frog saccular hair cells. Nat. Neurosci., 3, 786-790.

Felmy, F., Neher, E. \& Schneggenburger, R. (2003) Probing the intracellular calcium sensitivity of transmitter release during synaptic facilitation. Neuron, 37, 801-811.

Forsythe, I.D. (1994) Direct patch recording from identified presynaptic terminals mediating glutamatergic EPSCs in the rat CNS in vitro. J. Physiol. (Lond.), 479, 381-387.

Friauf, E. (1992) Tonotopic order in the adult and developing auditory system of the rat as shown by c-fos immunocytochemistry. Eur. J. Neurosci., 4, 798-812.

Friauf, E. (1993) Transient appearance of calbindin-D28k-positive neurons in the superior olivary complex of developing rats. J. Comp. Neurol., 334, $59-74$.

Friauf, E. \& Ostwald, J. (1988) Divergent projections of physiologically characterized rat ventral cochlear nucleus neurons as shown by intra-axonal injection of horseradish peroxidase. Exp. Brain Res., 73, 263-284.

von Gersdorff, H. \& Borst, J.G. (2002) Short-term plasticity at the calyx of held. Nat. Rev. Neurosci., 3, 53-64.

Grothe, B. (2003) New roles for synaptic inhibition in sound source localization. Nat. Rev. Neurosci., 4, 540-550.

Guinan, J.J., Norris, B.E. \& Guinan, S.S. (1972) Single auditory units in the superior olivary complex. Int. J. Neurosci., 4, 147-166.

Harrison, J.M. \& Irving, R. (1965) The anterior ventral cochlear nucleus. J. Comp. Neurol., 124, 15-42.

Harrison, J.M. \& Irving, R. (1966) Ascending connections of the anterior ventral cochlear nucleus in the rat. J. Comp. Neurol., 126, 51-64.
Helmchen, F., Borst, J.G. \& Sakmann, B. (1997) Calcium dynamics associated with a single action potential in a CNS presynaptic terminal. Biophys. J., 72, 1458-1471.

Iwasaki, S. \& Takahashi, T. (2001) Developmental regulation of transmitter release at the calyx of Held in rat auditory brainstem. J. Physiol. (Lond.), 534, 861-871.

Jewett, D.L. \& Romano, M.N. (1972) Neonatal development of auditory system potentials averaged from the scalp of rat and cat. Brain Res., 36, 101115.

Joshi, I. \& Wang, L.-Y. (2002) Developmental profiles of glutamate receptors and synaptic transmission at a single synapse in the mouse auditory brainstem. J. Physiol. (Lond.), 540, 861-873.

Kandler, K. \& Friauf, E. (1993) Pre- and postnatal development of efferent connections of the cochlear nucleus in the rat. J. Comp. Neurol., 328, 161184.

Kuwabara, N., DiCaprio, R.A. \& Zook, J.M. (1991) Afferents to the medial nucleus of the trapezoid body and their collateral projections. J. Comp. Neurol., 314, 684-706.

Lee, S.H., Schwaller, B. \& Neher, E. (2000) Kinetics of $\mathrm{Ca}^{2+}$ binding to parvalbumin in bovine chromaffin cells: implications for $\left[\mathrm{Ca}^{2+}\right]$ transients of neuronal dendrites. J. Physiol. (Lond.), 525, 419-432.

Lips, M.B. \& Keller, B.U. (1998) Endogenous calcium buffering in motoneurones of the nucleus hypoglossus from mouse. J. Physiol. (Lond.), 511, 105-117.

Lohmann, C. \& Friauf, E. (1996) Distribution of the calcium-binding proteins parvalbumin and calretinin in the auditory brainstem of adult and developing rats. J. Comp. Neurol., 367, 90-109.

Nägerl, U.V., Novo, D., Mody, I. \& Vergara, J.L. (2000) Binding kinetics of calbindin- $\mathrm{D}_{28 \mathrm{k}}$ determined by flash photolysis of caged $\mathrm{Ca}^{2+}$. Biophys. J., 79, 3009-3018.

Neher, E. (1998) Usefulness and limitations of linear approximations to the understanding of $\mathrm{Ca}^{++}$signals. Cell Calcium, 24, 345-357.

Resibois, A. \& Rogers, J.H. (1992) Calretinin in rat brain: an immunohistochemical study. Neuroscience, 46, 101-134.

Rogers, J.H. \& Resibois, A. (1992) Calretinin and calbindin-D28k in rat brain: patterns of partial co-localization. Neuroscience, 51, 843-865.

Rozov, A., Burnashev, N., Sakmann, B. \& Neher, E. (2001) Transmitter release modulation by intracellular $\mathrm{Ca}^{2+}$ buffers in facilitating and depressing nerve terminals of pyramidal cells in layer $2 / 3$ of the rat neocortex indicates a target cell-specific difference in presynaptic calcium dynamics. J. Physiol. (Lond.), 531, 807-826.

Saint Marie, R.L., Luo, L. \& Ryan, A.F. (1999) Effects of stimulus frequency and intensity on c-fos mRNA expression in the adult rat auditory brainstem. J. Comp. Neurol., 404, 258-270.

Schneggenburger, R., Meyer, A.C. \& Neher, E. (1999) Released fraction and total size of a pool of immediately available transmitter quanta at a calyx synapse. Neuron, 23, 399-409.

Schneggenburger, R., Sakaba, T. \& Neher, E. (2002) Vesicle pools and shortterm synaptic depression: lessons from a large synapse. Trends Neurosci., 25, 206-212.

Schurmans, S., Schiffmann, S.N., Gurden, H., Lemaire, M., Lipp, H.P., Schwam, V., Pochet, R., Imperato, A., Bohme, G.A. \& Parmentier, M. (1997) Impaired long-term potentiation induction in dentate gyrus of calretinin-deficient mice. Proc. Natl Acad. Sci. USA, 94, 10415-10420.

Spirou, G.A., Brownell, W.E. \& Zidnac, M. (1990) Recordings from cat trapezoid body and HRP labeling of globular bushy cell axons. J. Neurophysiol., 63, 1169-1190.

Taschenberger, H., Leao, R.M., Rowland, K.C., Spirou, G.A. \& von Gersdorff, H. (2002) Optimizing synaptic architecture and efficiency for high-frequency transmission. Neuron, 36, 1127-1143.

Taschenberger, H. \& von Gersdorff, H. (2000) Fine-tuning an auditory synapse for speed and fidelity: developmental changes in presynaptic waveform, EPSC kinetics, and synaptic plasticity. J. Neurosci., 20, 91629173.

Vreugdenhil, M., Jefferys, J.G., Celio, M.R. \& Schwaller, B. (2003) Parvalbumin-deficiency facilitates repetitive IPSCs and gamma oscillations in the hippocampus. J. Neurophysiol., 89, 1414-1422.

Webster, W.R., Batini, C., Buisseret-Delmas, C., Compoint, C., Guegan, M. \& Thomasset, M. (1990) Colocalization of calbindin and GABA in medial nucleus of the trapezoid body of the rat. Neurosci. Lett., 111, 252-257. 